\title{
NONSENSE E REPRESENTAÇÃO: ALICE E A RELAÇÃO COM O REAL
}

\author{
Isabella Pereira Marucci* \\ Ramiro Giroldo*
}

RESUMO: O presente artigo tem como objetivo a análise da relação entre o nonsense literário e o real nas obras Alice no País das Maravilhas e Através do Espelho e o que Alice encontrou por lá, ambas de Lewis Carroll. Busca-se compreender como configura uma representação da realidade ou daquilo que tomamos por real. Atribuindo-lhe assim, significado e reflexão acerca do conceito que, primariamente, remete a algo que "não possui sentido". O caminho que se pretende percorrer no trabalho começa com uma observação sobre a ocorrência do nonsense em Alice, aliando a teoria específica sobre; passando adiante para as concepções de representação. Para tanto, serão tomadas noções de representação em Adorno, Aristóteles, Benjamim, Auerbach, Barthes e considerações acerca do nonsense trabalhadas por Anthony Burgess.

PALAVRAS-CHAVE: Alice no pais das maravilhas; Lewis Carroll; Nonsense; Representação.

O nonsense literário é caracterizado, a princípio, pela falta de sentido. Como a nomenclatura alude por meio da composição de duas palavras para formarem uma terceira: há o non e sense, que traduzidas literalmente da língua inglesa, seria o "sem senso". Seriam as ideias absurdas que fogem da natureza que conhecemos, assim como situações bizarras, diálogos desconexos e palavras inventadas. Ele é conceituado dessa maneira como aponta Anthony Burgess: "Nonsense é propriamente uma coisa negativa - a falta de sentido" (BURGESS, 1986, p.17) ${ }^{1}$. Originado propriamente na Inglaterra, esse fenômeno carrega consigo a complexidade e contrariedade na sua concepção, pois apesar da visão geral (senso comum) de não ter significado, não seria aleatório ou desprovido de sentido totalmente. Constituiria algo muito além do que está posto superficialmente.

\footnotetext{
* Doutoranda em Estudos de Linguagens pela Universidade Federal de Mato Grosso do Sul (UFMS). Bolsista Fundect. Mestre em Estudos de Linguagens pela mesma instituição.

** Professor da Universidade Federal de Mato Grosso do Sul (UFMS). Doutor em Literatura pela Universidade de São Paulo (USP). Autor do livro Ditadura do pražer: sobre ficção científica e utopia (Editora da UFMS).

${ }^{1}$ Nonsense is properly a negative thing - a lack of sense. (BURGESS, 1986, p.17, tradução nossa.)
} 
Lewis Carroll foi um dos responsáveis pela difusão desse conceito, sendo duas das suas obras postas em análise aqui. Alice no País das Maravilhas conta a história da menina Alice que, entediada por não ter o que fazer em uma tarde ao ar livre, avista o Coelho Branco e decide segui-lo; ao fazê-lo acaba caindo em sua toca e depara-se no lugar chamado País das maravilhas, onde criaturas extraordinárias residem e são estruturados pelo nonsense. A regência do espaço se deve à Rainha de Copas, movida por intolerância e rigidez extrema.

De maneira semelhante, em Através do espelho e o que Alice encontrou por lá, Alice agora atravessa o espelho de sua sala de estar, após considerar em brincadeira com sua gata de estimação a existência de um possível universo alternativo. A travessia a leva para o Mundo dos espelhos que, diferentemente do País das maravilhas, é construído com base em um jogo de xadrez, o qual Alice deve vencer para se tornar uma rainha, ao lado da Rainha Branca e a Rainha Vermelha, personagem problematizada como a Rainha de Copas em suas ideologias.

Não compreendendo a construção dessas sociedades que são em muito distantes do "real", por conta das características do nonsense que a perpassam e as afastam da ideia de realidade que temos, Alice é colocada como uma figura questionadora, que sempre problematiza as práticas daqueles lugares e não teme possíveis enfrentamentos com as autoridades, principalmente e explicitamente a Rainha de Copas. É importante ressaltar para início que essa estranheza por parte de Alice só é possível pelo nonsense. É por meio dele que sua atenção é chamada e voltada para a reflexão. $\mathrm{O}$ fato dos universos serem diferentes do que ela conhece a leva ao estado de oposição.

O nonsense pode ser considerado, segundo Anthony Burgess, como: "De fato, a tradição nonsense britânica, como a surrealista que a sucedeu, é apenas uma maneira bizarra de fazer sentido" (BURGESS, 1986. p.21). ${ }^{2}$ Isto é, seu primeiro impacto parece demonstrar que não há lógica ou sentido em suas proposições, mas ao contrário, seria uma maneira

\footnotetext{
${ }^{2}$ In fact, the British nonsense tradition, like the surrealist one which succeeded it, is only a bizarre way of making sense (BURGESS, 1986, p.21). (Tradução nossa).
} 
distanciada do real que pode suscitar e provocar reflexões. Interessante citar que sua origem é inglesa, nascido no contexto da Inglaterra Vitoriana, período conturbado, de severas ideologias e posições conservadoras.

Embora não seja possível realizar afirmações e nem dar ao nonsense características únicas, diante da sua ampla flexibilidade e possibilidades interpretativas, uma das possíveis leituras seria de que o contexto sócio histórico teria servido como fator predominante para o desenrolar da história de Alice; as inevitáveis correlações entre o nonsense literário e o real aludem ao seu caráter representativo defronte certas perspectivas de realidade e cunho social. No entanto, embora esta não seja a problemática central deste artigo, sua menção vale pela relevância para tratar de outras questões concernentes.

Essa condição estaria intrinsecamente ligada à ideia de escurecimento de Auerbach, que coloca os textos literários divididos entre duas instâncias: os mais próximos do texto homérico e os que se aproximam mais do texto bíblico, em menor ou maior grau. Essa divisão se baseia na contradição que os dois produzem, sendo o texto homérico totalmente aclarado, com as coisas explicitamente ditas e detalhadas em pormenores para o leitor, isto é, tudo é determinado para a experiência total. Enquanto que no texto bíblico se dá ao contrário, tudo é complexo, escurecido ao leitor, cheio de lacunas em aberto para as interpretações que possam advir dessas indeterminações:

De um lado, fenômenos acabados, uniformemente iluminados, definidos temporal e espacialmente, ligados entre si, sem interstícios, num primeiro plano; pensamentos e sentimentos expressos; acontecimentos que se desenvolvem com muito vagar e pouca tensão. Do outro lado, só é acabado formalmente aquilo que nas manifestações interessa à meta da ação; o restante fica na escuridão. Os pontos culminantes e decisivos para a ação são os únicos a serem salientados; o que há entre eles é inconsistente; tempo e espaço são indefinidos e precisam de interpretação; os pensamentos e os sentimentos permanecem inexpressos: só são sugeridos pelo silêncio e por discursos fragmentários. (AUERBACH, 2013, p.9)

Diante dessa perspectiva, as aventuras de Alice estariam mais próximas da Bíblia por essa questão obscura, nada é explícito ou devidamente explicado, por conta do nonsense literário, que vem a indeterminar por meio da falta de detalhes, causando um sentido 
metonímico, de maneira a ficar aberta a possíveis interpretações por parte dos leitores. Há esse escurecimento, como no trecho bíblico que, diferentemente do homérico que busca aclarar tudo ao leitor (rico em detalhes), deixa trechos em aberto porque a experiência total não é possível. Está além do nosso nível sensível: "No relato bíblico também se fala; mas o discurso não tem, como em Homero, a função de manifestar ou exteriorizar pensamentos. Antes pelo contrário: tem a intenção de aludir a algo implícito, que permanece inexpresso." (AUERBACH, 2013, p.8)

Ainda que tanto em Alice no país das maravilhas como em Através do espelho e o que Alice encontrou por lá seja possível fazer relações com o contexto sócio histórico, como mencionado anteriormente, isso não está explicitado no texto, é uma das possíveis leituras, além de servir para pensar outros contextos. A obscuridade e complexidade do nonsense, como podem ser relacionadas em Auerbach, é apresentado nas obras de Carroll de diferentes maneiras, como em diálogos desconexos e ocorrências bizarras. Um exemplo de nonsense em Alice em questão situacional:

\begin{abstract}
"Que sensação estranha!” disse Alice; “devo estar encolhendo como um telescópio!" E estava mesmo: agora só tinha vinte e cinco centímetros de altura e seu rosto se iluminou à ideia de que chegara ao tamanho certo para passar pela portinha e chegar àquele jardim encantador. Primeiro, no entanto, esperou alguns minutos para ver se ia encolher ainda mais: a ideia a deixou um pouco nervosa; "pois isso poderia acabar", disse Alice consigo mesma, "me fazendo sumir completamente, como uma vela. Nesse caso, como eu seria?" E tentou imaginar como é a chama de uma vela depois que a vela se apaga, pois não conseguia se lembrar de jamais ter visto tal coisa. (CARROLL, 2013, p.14)
\end{abstract}

As oscilações na altura de Alice é algo que causa estranheza porque não há uma explicação plausível para tal, geralmente ocorrem no enredo aparentemente de forma despropositada, assim como as inúmeras outras situações que são características do País das maravilhas e dos espelhos. A distância tomada do real para sua concepção é o que contribui para o efeito que o escurecimento causa, que no caso específico das obras aqui citadas, seriam ampliadas pela ação do nonsense, o que afirma que ambos possuem essa relação; exemplo de nonsense em diálogos: 
(...) "Porque um corvo se parece com uma escrivaninha?"

"Oba, vou me divertir um pouco agora!" pensou Alice. "Que bom que tenham começado a propor adivinhações". E acrescentou em vOz alta: "Acho que posso matar esta."

"Está sugerindo que pode achar a resposta?" perguntou a Lebre de Março.

"Exatamente isso", declarou Alice.

"Então deveria dizer o que pensa", a Lebre de Março continuou.

"Eu digo", Alice respondeu apressadamente; "pelo menos...pelo menos eu penso o que digo...é a mesma coisa, não?"

"Nem de longe a mesma coisa!" disse o Chapeleiro. "Seria como dizer que ‘vejo o que como' é a mesma coisa que 'como o que vejo'!”

"Ou o mesmo que dizer", acrescentou a Lebre de Março, "que 'aprecio o que tenho' é a mesma coisa que 'tenho o que aprecio'?"

"Ou o mesmo que dizer", acrescentou o Caxinguelê, que parecia estar falando dormindo, “que 'respiro quando durmo' é a mesma coisa que 'durmo quando respiro'?” (CARROLL, 2013, p.55)

As ideias desconexas levantadas pelos personagens habitantes do universo nonsense, nas suas diversas interações com Alice, podem remeter às diferentes referências que cada um dos envolvidos tem. Acontece que é necessário considerar que Alice não pertence aquele lugar, ela encontrava-se no mundo "real" e transita para um espaço estruturado em oposição ao que ela conhece, o que auxilia também na estranheza e contradição entre os comportamentos, visões e opiniões. Pois para os que vivem no País das maravilhas e dos espelhos, aquela é a única verdade que existe, pois é a única que partilham; sendo assim, Alice é uma espécie de intrusa por sempre questioná-los e contradizê-los.

À exemplo do diálogo citado, vemos que o modo de pensar de Alice em muito se diferencia dos demais na cena: Chapeleiro Maluco, Lebre de Março e Caxinguelê, que concordam uns com os outros em oposição à Alice, por compartilharem da mesma visão de mundo. É importante ressaltar que o nonsense aqui aparece por meio do jogo de palavras, invertendo a ordem dos termos na frase para criar diferentes sentidos. Enquanto Alice não considera essa questão, os personagens apontam inúmeros momentos em que essa ordem pode causar diferentes efeitos. Essa proposição pode indicar uma atenção especial ao nonsense, ao qual não se deveria imputar significados como certos e únicos ou julgá-lo prontamente, limitando-o; pois o alcance do nonsense, nesse patamar, é infinito. Reafirmando uma 
vez mais a presente obscuridade de Auerbach, e as várias interpretações possíveis em torno da sua indeterminação.

O fato dessa condição não ser levada em consideração, leva a banalização do nonsense literário, ao pré-julgamento de sua falta de sentido. Burgess discute sobre essa repulsa ao nonsense, como advinda da lógica cartesiana:

Estupidez, ou ilogismo, (nonsense) pode ser nomeado pragmatismo. Pessoas pragmáticas irão aceitar o nonsense, esperando que essa experiência irá provar que há sentido nele. As pessoas lógicas rejeitam o nonsense de uma vez por todas, pelas regras do argumento Cartesiano não requerem experiência para ratifićá-lo. (BURGESS, 1986, p.17) ${ }^{3}$

Burgess fala também especificamente sobre o nonsense de Carroll: Uma possível razão para tornar o nonsense nas aventuras de Alice "mais aceito" seria a questão do sonho (onírico), que se relaciona com Adorno também, como uma forma de afirmar a não aleatoriedade do nonsense, provando haver uma intenção significativa por trás.

O problema com o nonsense em sonhos é que não é puro nonsense. O cérebro humano é muito sensível para perder tempo em gerar o que não é biologicamente útil. Sonhos têm que ter significado, e os analistas freudianos têm feito um trabalho curto da infinita queda no buraco de Coelho e das coisas que acontecem no país das maravilhas. (BURGESS, 1986, p.20) ${ }^{4}$

Tendo em vista que a questão onírica causa ao mesmo tempo um distanciamento e aproximação do real, primeiro por conta de ser justificável qualquer acontecimento pelo nível do sonho; e segundo, pela assertiva de Burgess ao chamar a atenção para a relação com a realidade que os sonhos mantêm, criando um paralelo com a dualidade do nonsense (o "irreal") e o real. Trazendo uma questão importante para a concepção do fenômeno:

\footnotetext{
${ }^{3}$ Stupidity, or illogicality, can be termed pragmatism. Pragmatic people will accept nonsense, hoping that experience will prove there is sense in it. Logical people reject nonsense at once and forever, for the rules of Cartesian argument do not require experience to ratify them. (BURGESS, 1986, p.17, tradução nossa.)

${ }^{4}$ The trouble with nonsense in dreams is that it is not pure nonsense. The human brain is too sensible to waste its time on generating what is not biologically useful. Dreams have to have meaning, and Freudian analysts have made short work of the endless fall down the rabbit hole and the things that happen in Wonderland (BURGESS, 1986, p. 20, tradução nossa.)
} 
Qual a "função" do nonsense nas narrativas de Alice? Se ele é visto como esse ponto negativo de não possuir sentido, de não ser relevante, porque ele está sendo usado?

Alice considera algo que corrobora com a discussão. Durante todo o enredo das obras, a personagem demonstra uma relação complicada com o nonsense literário, sua relação com o lugar se dá por constantes oscilações. Ela parece em alguns momentos estar tão maravilhada e acostumada com as ocorrências absurdas que acha inconveniente quando não estão presentes: “(...) Alice tinha se acostumado tanto a esperar só coisas esquisitas acontecerem que lhe parecia muito sem graça e maçante que a vida seguisse da maneira habitual." (CARROLL, 2013, p.15). Mas, em outros momentos, demonstra relutância à constituição do País das maravilhas, reagindo ao extremo oposto: "Alice não disse nada; sentara-se com a cabeça nas mãos, perguntando a si mesma se algum dia alguma coisa voltaria a acontecer de maneira natural." (CARROLL, 2013, p.85).

A primeira coisa a se notar diante da visão confusa de Alice, é que tanto o País das Maravilhas como o País dos Espelhos possuem uma lógica interna, uma "verdade” própria. Nos parâmetros daquela ambientação literária, o universo funciona. Razão pela qual os demais personagens habitantes daquele contexto não percebem o absurdo ao redor, como mencionado anteriormente. Essa condição está relacionada à questão mimética e de verossimilhança de Aristóteles, considerando o nonsense como representação do real: "É claro, também, pelo que atrás ficou dito, que a obra do poeta não consiste em contar o que aconteceu, mas sim coisas quais podiam acontecer, possíveis no ponto de vista da verossimilhança ou da necessidade” (ARISTÓTELES, p.28).

Segundo o autor, cada obra cria a sua verdade, sendo desnecessária sua constante comparação com aquilo que tomamos como "verdade" (o "real"). Diante dessa perspectiva, o nonsense vai fazer sentido porque vai cunhar sua própria verdade e significado:

De modo geral, o impossível se deve reportar ao efeito poético, à melhoria, ou à opinião comum. Do ângulo da poesia, um impossível convincente é preferível a um possível que não convença (...). As absurdezas devem-se reportar à tradição; assim, também se dirá, por vezes, que não se trata dum absurdo, pois é verossímil que algo aconteça contra a verossimilhança. (ARISTÓTELES, p.50 e 51) 
O fato de Alice "não aceitar" o nonsense, sempre o questionando, poderia significar que ela desconsidera essa lógica interna criada, pois o que conhece como realidade seria bastante distanciada do que lhe é apresentado nas duas oportunidades. No entanto, as motivações seriam mais complexas, como veremos adiante. Ainda acerca das opiniões contraditórias de Alice sobre o nonsense, em determinado momento, ao sentir-se perdida naquele espaço, ela diz: “Ai, ai! Como tudo está esquisito hoje! E ontem as coisas aconteciam exatamente como de costume. Será que fui trocada durante a noite? (...)" (CARROLL, 2013, p.17).

A partir dessa frase vemos a conexão entre o nonsense e o real, sendo possível enxergá-lo como uma representação da realidade. Tanto o País das maravilhas como o dos espelhos têm como governante a figura da Rainha. Essa detém todo o poder e é a única a ordenar o âmbito, os demais personagens não possuem voz nesse contexto, ao contrário, se ousarem ir contra as ideologias da Rainha de Copas, serão condenados à guilhotina. Esse é o problema principal daquela sociedade, o autoritarismo da Rainha que acredita ser a detentora do saber: "A Rainha só tinha uma maneira de resolver todas as dificuldades, grandes ou pequenas. "Cortem-lhe a cabeça!” ordenou sem pestanejar.” (CARROLL, 2013, p.69).

Muitas são as cenas que mostram a forma do tratamento, por parte da Rainha, para com o povo habitante. Em alguns momentos apenas julga que estão errados e não espera que se justifiquem, acabando por tirar suas próprias conclusões. Como é o que acontece quando surpreende os jardineiros pintando as rosas brancas de cor vermelha:

\footnotetext{
"O que andaram fazendo aqui?"

"Que seja do agrado de Vossa Majestade", disse o Dois num tom muito humilde, pondo um joelho no chão enquanto falava; “estávamos tentando..."

"Entendo!" disse a Rainha, que nesse meio-tempo estivera examinando as rosas. "Cortem-lhes as cabeças!" (CARROLL, 2013, p. 66)
}

Os jardineiros haviam plantado enganosamente rosas brancas no lugar das vermelhas exigidas pela Rainha e, movidos pelo desespero de que ela viesse a tomar conhecimento, encontram como única solução pintarem as rosas com tinta; esse ato se deve pelo 
fato de saberem que a intolerância da autoridade não a deixaria relevar o erro cometido, e por isso já estavam condenados. Era uma tentativa de não sofrer as consequências opressivas, o que não foi bem sucedido; embora Alice tenha os salvado da guilhotina escondendo-os da visão da Rainha.

Esse também é o momento do primeiro encontro entre as personagens principais dos enredos, Alice e a Rainha. A interação já demonstra o descontentamento da menina com toda a situação e estrutura do lugar, respondendo rispidamente à Rainha de Copas, apresentando também a peculiaridade do comportamento de Alice, que se opõe frente às autoridades e situações que considera problemáticas.

"E quem são esses?" quis saber a Rainha apontando os três jardineiros deitados em volta da roseira; pois, como estavam de bruços e tinham nas costas o mesmo padrão que o resto do baralho, ela não tinha como saber se eram jardineiros, soldados, cortesãos ou três dos seus próprios filhos.

"Como eu poderia saber?" disse Alice, surpresa com a própria coragem. "Isso não é da minha conta."

A Rainha ficou rubra de fúria, e depois de fuzilá-la com os olhos por um momento como uma fera selvagem gritou: "Cortem-lhe a cabeça! Cortem..."

"Disparate!" disse Alice decidida, alto e bom som, e a Rainha se calou. (CARROLL, 2013, p.65)

A personalidade de Alice foge do que é esperado, devido às construções sociais que permeiam e procuram controlar o modo de pensar e agir dos indivíduos; relacionando-se à questão das molduras, de Luiz Costa Lima em Representação social e mímesis. As molduras seriam uma maneira de classificação na representação, onde se estipula características a uma determinada classe de pessoas. É uma maneira de classificar o outro, atribuindo-lhe sentido. No caso de Alice são duas as possibilidades de moldura: a primeira seria pela sua idade, por ser criança não era permitido que tivesse certas atitudes; mesmo que não seja o objetivo deste artigo realizar um recorte social, é possível aludir à época em que os textos foram escritos, período conservador:

Era muito fácil dizer "Beba-me", mas a ajuizada pequena Alice não iria fazer isso assim às pressas. "Não, primeiro vou olhar", disse, "e ver se está escrito 'veneno' ou não”; pois lera muitas historinhas 
divertidas sobre crianças que tinham ficado queimadas e sido comidas por animais selvagens e outras coisas desagradáveis, tudo porque não se lembravam das regrinhas simples que seus amigos lhes haviam ensinado. (CARROLL, 2013, p.13)

Nesse trecho se pode observar a referência que Alice faz às histórias com moral ao final, como fábulas, realizadas justamente para mostrar às crianças como devem se comportar, pois do contrário podem resultar em consequências desagradáveis. É interessante notar que a personagem tem consciência disso, da existência desse padrão comportamental, ainda que implicitamente, e mesmo assim suas ações em geral são contrárias, pelas posições firmes e irredutíveis diante dos diferentes contextos.

A segunda possibilidade de moldura se refere ao contexto em geral que ela está inserida, pois do ponto de vista social do reinado da Rainha de Copas, por exemplo, ninguém pode opinar, contrariar ou qualquer atitude que não coincida com os ideais da majestade. E nisso, Alice também age diferente do esperado e pautado, pois é a primeira que confronta o que acha estar errado e problemático. Esses traços da menina vão de encontro com o conceito de Keying:

(...) contentamo-nos em afirmar que o keying consiste no procedimento pelo qual um agente realiza um conjunto de ações que, do ponto de vista da moldura básica (primary frame) teria um significado que, entretanto, aí não se aplica. (...). O destinatário reage de maneira diversa ao que dele seria de esperar. (LIMA, 1981, p.224)

Alice quebra o conceito de moldura, pois não age da maneira que se é esperada que ela aja. Assim como o termo Keying, se configura como um sujeito que está em uma moldura, mas age de forma que não condiz, não é o esperado dentro dessa classificação. Estando a frente do seu tempo, por assim dizer, ela provoca reflexões e mudanças que irão impactar o ambiente em que está, pois se agisse da forma que lhe foi imposta, não haveria a possibilidade de confronto com o contexto opressor.

A divergência nas atitudes de Alice é um contraponto às reações dos demais personagens ao contexto posto, pois é a única que parece perceber as desigualdades sociais e os problemas advindos disso, enfrentando as situações sem temer as consequências; é igualmente um ponto crucial para a representação do real realizado pelo nonsense. Personagens 
que cruzam o caminho da menina e estabelecem diálogos com ela, como o Coelho Branco, Chapeleiro Maluco, Lebre de Março e Gato de Cheshire, não apresentam essa vontade de se opor à opressão, ou ainda sequer demonstram qualquer indício que conseguem, ao menos, reconhecer a existência da problemática.

Comportamento tal estaria ligado ao conceito de "estado de alerta", cunhado por Walter Benjamin, que seria o ato de se estar sempre atento, sob o risco de morrer se não haver essa atenção. É justamente a condição na qual vivem os personagens daquele universo absurdo, estão sempre preocupados em manterem-se vivos, pois qualquer ação pode levá-los à morte pelas mãos da Rainha. Intolerante como é seu governo, cria uma tensão entre o povo, que vive alienado ao que acontece ao redor, temendo serem condenados à guilhotina a qualquer momento: “(...) e nesse caso”, pensou, “que seria de mim? Eles são horrivelmente chegados a decapitar as pessoas aqui; o que me admira é que ainda sobre alguém vivo!" (CARROLL, 2013, p.68).

Mas o fato de Alice não pertencer àquele lugar, como citado anteriormente, não só abre portas para que ela enxergue mais claramente o contexto, como é por si só uma metáfora, porque na verdade, nessa proposição, os dois lugares (país das maravilhas/dos espelhos e "real") seriam o mesmo espaço. Acontece que Alice teve seus olhos abertos às coisas que se sucediam além da superfície, atrás da fachada conceituada por Adorno. Considerando que nos é apresentado uma fachada, que seria apenas a aparência, onde não haveria nada errado acontecendo no lugar em que estamos inseridos. Mas é apenas o que podemos enxergar, por trás dessa fachada, ou seja, na prática, as coisas não são como o que nos é passado. E só é possível perceber essa realidade ao perceber as rachaduras na fachada.

Adorno diz que "se o romance quiser permanecer fiel à sua herança realista e dizer como realmente as coisas são, então ele precisa renunciar a um realismo que, na medida em que reproduz a fachada, apenas a auxilia na produção do engodo" (ADORNO, 2003, p.57); corroborando com a sua premissa, a concepção do País das maravilhas seria a representação da verdadeira essência da fachada, possível por meio do nonsense. Antes de todos os acontecimentos se sucederem, Alice encontrava-se tranquila ao lado de sua irmã, e ao 
considerar mais tarde diante dos absurdos, retomando a sua citação anteriormente, que "ontem" as coisas aconteciam normalmente e hoje não mais, ela estaria aludindo ao fato de ter percebido as rachaduras na fachada e a atravessado.

A travessia teria se dado por meio da queda na toca do Coelho Branco, foi o momento de transição entre as duas condições da menina, de estar em estado de ignorância antes e ter seus olhos abertos depois. Os demais personagens não o podem perceber justamente por estarem no estado de alerta, o que não os permite enxergar o que está ao redor, devido à constante preocupação com suas vidas. Nesse sentido, o nonsense viria como um efeito ampliador da representação do real, um real que, assim como apontado por Adorno, não poderia ser simplesmente uma cópia daquilo que temos por verdade, pois se assim fosse, não haveria o impacto causado da quebra da fachada. É necessário que haja um choque, para que se consiga fazer refletir sobre a verdadeira essência, e esse choque é realizado por meio do nonsense literário:

O procedimento de Kafka, que encolhe completamente a distância, pode ser incluído entre os casos extremos, nos quais é possível aprender mais sobre o romance contemporâneo do que em qualquer das assim chamadas situações médias "típicas". Por meio de choques ele destrói no leitor a tranqüilidade contemplativa diante da coisa lida. Seus romances, se é que de fato eles ainda cabem nesse conceito, são a resposta antecipada a uma constituição do mundo na qual a atitude contemplativa tornou-se um sarcasmo sangrento, porque a permanente ameaça da catástrofe não permite mais a observação imparcial, e nem mesmo a imitação estética dessa situação. (ADORNO, 2003, p.61).

O nonsense é a ameaça constante da quebra da fachada, de que a qualquer momento se pode perder o chão determinado pela aparência, vendo a realidade por traz do que é dito. A constituição do País das Maravilhas seria a representação dessa ruptura, tão bem quanto o Coelho Branco, que foi o personagem responsável pela possibilidade de percepção dessa ruptura, pois quando Alice o avistou e decidiu persegui-lo, abriu portas para que saísse da condição ignorante e alienada, como uma escolha implícita. O choque causado pelo nonsense causa uma desautomatização do pensamento, não é o simples impacto de 
sentimentos, mas vai de encontro com a quebra da fachada de fato; pois se a escrita fosse apenas realista, seria simplesmente automática, sem o risco de ruptura da aparência.

Encarando o nonsense como a desestruturação da ideia de verdade e/ou real que temos primariamente e a relação que mantém com os conceitos de Adorno e Benjamin, é possível compreender também a possível razão para o uso desse fenômeno para criar a dissociação e consequente choque no leitor. Acontece que a experiência do trauma não permite o sujeito narrar de forma precisa. Em vários contextos, Alice se esquece de conceitos básicos, além dos vários diálogos desconexos entre os personagens, como se as ideias estivessem soltas, jogadas.

“(...) Vou experimentar para ver se sei tudo que sabia antes. Deixeme ver: quatro vezes cinco é doze, e quatro vezes seis é treze, e quatro vezes sete é...ai, ai! (...) vamos tentar Geografia. Londres é a capital de Paris, e Paris é a capital de Roma, e Roma...não, está tudo errado, eu sei! (...)" (CARROLL, 2013, p.18)

Assim sendo, a melhor maneira de contar a história seria se afastando dela, porque ao tomar distância torna-se possível a explicação pela impossibilidade do narrar, uma vez inserido no contexto traumático. Essa seria uma das razões para o uso do nonsense. Alice teria recorrido implicitamente ao sonho para contar sua história, como dito anteriormente, uma especificidade das obras de Carroll que, nas duas oportunidades, revelou que Alice estava a sonhar, ou seja, são constituídas uma forma dupla de dissociação: o sonho e nonsense, pois ambos se afastam do real para dele falar.

Mas ao mesmo tempo cria outra problemática, pois como o nonsense seria confiável, enquanto forma representativa, já que há a necessidade de se distanciar daquilo que se representa, no caso o real, para dele melhor falar? É necessário considerar que em qualquer narrativa dissociativa haverá a dificuldade em atribuir sentido e em representar. Isso se deve pela causa de que a dissociação quebra a narração e experiência. O que, por sua vez, auxilia na compreensão do nonsense, que, sendo a quebra de sentido, afirma-se na concepção de que apenas assim consegue representar o vivido, o real. 


\section{NONSENSE AND REPRESENTATION: ALICE AND THE RELATIONSHIP WITH THE REAL}

ABSTRACT: This article aims to analyze the relationship between the literary nonsense and the real in the works Alice in Wonderland and Through the Looking Glass and what Alice found there, both by Lewis Carroll. It tries to understand how it configures a representation of reality or of what we take for real. Attributing to it, meaning and reflection about the concept that, primarily, refers to something that "has no meaning". The path we are going to go through at work begins with an observation about the occurrence of nonsense in Alice, combining the specific theory about; passing on to conceptions of representation. To this end, notions of representation will be taken in Adorno, Aristotle, Benjamin, Auerbach, Barthes, and nonsense considerations by Anthony Burgess.

KEYWORDS: Alice in wonderland; Lewis Carroll; Nonsense; Representation.

\section{REFERÊNCIAS}

ADORNO, Theodor. Posição do narrador no romance contemporâneo. In: Notas de Literatura I. Tradução Jorge de Almeida. São Paulo: 34 Letras, 2003.

ARISTÓTELES. A poética clássica. Aristóteles, Horácio, Longino. Tradução Jaime Bruna. 12. ed. São Paulo. Editora Cultrix, 2005.

AUERBACH, Erich. A cicatriz de Ulisses. In: . Mimesis: a representação da realidade na literatura ocidental. 6 ed. São Paulo: Perspectiva, 2013.

BENJAMIN, Walter. O narrador: considerações sobre a obra de Nikolai Leskov. In: . Obras escolbidas. 1. ed., vol. 1. São Paulo, Brasiliense, 1936.

BURGESS, Anthony. Nonsense. 1986. In: Exploration in the Field of nonsense. Organizado por W. Tigges. Amsterdam. Editora Rodopi. 1987.

CARrOLL, Lewis. Aventuras de Alice no País das Maravilhas \& Através do Espelho. Rio de Janeiro. Editora Zahar. 2013.

LIMA, Luiz Costa. Representação social e mímesis? In: Dispersa demanda. Rio de Janeiro: Francisco Alves, 1981.

Recebido em: 25/11/2020.

Aprovado em: 15/01/ 2021. 